\title{
Epidemiology of Tumors of the Brain and Central Nervous System: Review of Incidence and Patterns among Histological Subtypes
}

\author{
Dimitris Vovoras ${ }^{1}$, Keshav P. Pokhrel ${ }^{2}$, Chris P. Tsokos ${ }^{3}$ \\ ${ }^{1}$ Tampa, USA \\ ${ }^{2}$ Department of Mathematics and Computer Systems, Mercyhurst University, Erie, PA, USA \\ ${ }^{3}$ Department of Mathematics \& Statistics, University of South Florida, Tampa, FL, USA \\ Email: dvovoras@mail.usf.edu
}

Received 25 August 2014; revised 25 September 2014; accepted 25 October 2014

Copyright (C) 2014 by authors and Scientific Research Publishing Inc.

This work is licensed under the Creative Commons Attribution International License (CC BY). http://creativecommons.org/licenses/by/4.0/

(c) (;) Open Access

\begin{abstract}
Most epidemiology reports indicate that brain tumor rates in whites are higher than other populations and that they are more common in males than females. In this report, we analyze incidence patterns in registry data from the Surveillance, Epidemiology, and End Results program in different histological groups, racial/gender combinations and compare the overall and age-specific incidence rates. Our analysis shows statistically significant racial differences in rates for astrocytomas non-otherwise specified in both sexes, and unspecified malignant intracranial intraspinal neoplasms for females. Those of other specified intracranial and intraspinal neoplasms in females are higher than males, indicating the importance of biological differences. Other glioma young age rates peak after the age of five, the peak is higher for the black race. The study demonstrated several distinctive patterns in the rates by histological subtypes and showed differentiation in the age at diagnosis, giving insight on potential true changes in different subpopulations.
\end{abstract}

\section{Keywords}

Incidence, SEER, Brain and CNS Tumors, Demographic

\section{Introduction}

Epidemiological data on the full scale of primary brain and central nervous system in the USA can be found from Surveillance Epidemiology and End Results (SEER), North American Association of Central Cancer Regi-

How to cite this paper: Vovoras, D., Pokhrel, K.P. and Tsokos, C.P. (2014) Epidemiology of Tumors of the Brain and Central Nervous System: Review of Incidence and Patterns among Histological Subtypes. Open Journal of Epidemiology, 4, $224-234$. http://dx.doi.org/10.4236/ojepi.2014.44029 
stries and the Central Brain Tumor Registry of the United States (CBTRUS), their latest reviews are reported in [1], [2]. Characteristics of the three databases are reviewed and relevant information on brain tumors is discussed in [3]. Variation in adult brain cancer incidence for grouped populations in an international level has been studied in [4]. Incidence rates from regional population based registries in Japan are evaluated in [5] and Northern Europe in [6].

Epidemiologic studies of brain and Central Nervous System (CNS) tumors have examined survival and incidence rates over the past decades presenting the most recent data on rates and trends of brain tumor histological diversity. Concerns with regard to brain tumor risk are increasing and epidemiologic studies have examined available evidence over the past decades. A major priority has been to find differences between incidence and survival experienced by the subjects based on their biological diversity. Since any new treatments have limited ability to improve prognosis for all brain tumors histology type, grade, age, tumor location are mostly linked to survival times.

While progress in diagnostic technologies may have contributed to an increase in incidence for several histologies, changes in brain tumor classifications are also likely to be responsible for shifting towards certain brain tumor histologies. Studies intending to update information and provide detailed perspectives on the epidemiology of primary brain tumors in the USA are increasingly prompting debates on weather changes in the trends reflect changes in etiology or cases ascertainment.

In the following we include an overview of the literature on incidence rates, not intended as an exhaustive coverage of the relevant studies, but as a presentation of studies with various priorities and evidence.

A brief description of the literature since 2001 for major molecular, genetics findings is discussed in [7]-[13]. Already established and new emerging risk factors are discussed in [14]-[18]. For developments in pediatric tumors research we refer to [19]-[26]. Brain tumors incidence trends and new diagnostic tools are discussed in [27]-[32]. For discussions about prioritized areas for further research, and consensus on available evidence, see [33]-[36]. Epidemiologic findings for brain tumors and methods of classification are reported in [37]-[47].

In this study we employ descriptive and statistical methods to update the incidence of brain tumors and provide information on occurrence by sex, age and race. If the variation in incidence rates among the registries represents differences in incidence experienced by the population then the registered brain tumors represent the variation of brain cancer incidences in USA. Our estimates showed i) sex differences with demonstrated distinctive patterns on the incidence rates depending on histologies; ii) racial differences in specific rates in several histologies giving insight into possible etiologies of brain tumors. An effort is undertaken to better characterize pediatric brain tumor incidence, with an emphasis on improving our understanding on racial and gender differences. Analysis of malignant tumors is based on data between 1973 and 2010 for a broad spectrum of histologies.

\section{Methods}

The National Cancer Institute's SEER program provides information and other comprehensive resources with regard to incidence on tumors from various US metropolitan areas.

In summary, the program collects information on incidence from specific geographic areas representing 28 percent of the US population and compile reports for the entire country through the SEER program. Conventionally, the risk is evaluated by incidence rates; in some instances these statistics are reported by histology classifications, race, sex, tumor location and grade. The following nine registries provided data on the incidences of brain tumors diagnosed between 1973 and 2010: San Francisco-Oakland SMSA-1973+, Connecticut-1973+, Detroit (Metropolitan)-1973+, Hawaii-1973+, Iowa-1973+, New Mexico-1973+, Seattle (Puget Sound)-1974+, Utah-1973+, Atlanta (Metropolitan)-1975+. All the tumors included in the study were malignant, primary tumors of the brain and the central nervous system, site codes are C000-C809 and ICD-O-3 histology codes are 9161 9571 as well as $8000-8005$, finally, 0,1 and 3 are the ICD-O-3 behavior recodes [48]. For definitions of the primary sites, ICD-O-3 behavior recodes and histology, see [49]. Available information included gender, race, age at diagnosis and type of histology; for more details see [50].

Age-adjusted incidence rates per 100,000 persons based on the 2000 standard US population were extracted using the SEER*Stat 8.0.4 software of the Surveillance Epidemiology and End Results program, National Cancer Institute. Between 1973 and 2010, 57,343 cases of malignant brain tumors were diagnosed in the nine SEER registries and recorded in the data released in April 2013 with complete data on sex, race, and birth date, year and age at diagnosis, histological diagnosis. Rate calculations include crude rates for white, black, and American In- 
dian/Alaska native, Asian/Pacific islander populations; consequently the detail statistics of incidence rates may not be available in some cases. Included in the SEER datasets is the "other unspecified" race. Since the information for this group is very sparse, we decided not to include this racial group in the analysis.

Brain and CNS tumors are classified according to the adolescents and young adults (AYA) site recode variable based on the classification scheme in [50]. Incidence rates are reported for ten histologies: specified low grade astrocytic tumor, glioblastoma and anaplastic astrocytoma, astrocytoma NOS are the astrocytic histologies, other glioma, ependynoma, medulloblastoma, supratentorial PNET, other specified intracranial and intraspinal neoplasms, unspecified malignant intracranial intraspinal neoplasm, unspecified benign/boarder intracranial intraspinal neoplasm. In this study we will attempt to compare rates for those histologies that allowed for comparisons between all sex, race and age groups, the last histology was excluded because of the insufficient number of records. A risk-adjusted method proposed for estimating cancer incidence rates from data collected by the SEER program of the US National Cancer Institute is used when comparing rates in different races.

Characteristics of the available primary brain and other CNS tumors patients during the study period are shown in Table 1. Relative frequencies by histology subtypes in all male and female racial groups are presented for the 1973-2010 period. The frequencies for three age groups and histological subtypes are reported for the same period. The majority (53.2\%) of the tumors are in the 20 - 64 year age group, while $33.8 \%$ of the tumors occurred in the elderly and the remaining $13 \%$ of the tumors occurred in children. The percentage of brain tumors in the data by gender is $55.6 \%$ for males and $45.4 \%$ for female; the number of incidence cases is dramatically higher in whites $89.5 \%$ of the recorded tumors.

\section{Results}

Annual incidence rates and corresponding confidence intervals (CI) for all brain tumors ranged from 6.87 (95\% CI 6.79 - 6.93) to 3.29 (95\% CI 3.16 - 3.41), and 2.95 (95\% CI 2.82 - 3.08) cases per 100,000 for the white, black and other race, respectively. The increased incidence rates for whites compared with other races is statistically significant ( $\mathrm{p}<0.05$ ) is apparent by the non-overlapping CI's. The distribution of races was shown in Table 1, corresponding relative risks were 2.09 for whites versus blacks and 2.33 when whites are compared with the other group. Exact rate ratio tests assuming Poisson count, see [51], for the populations gave 95\% confidence intervals for the whites over blacks, whites over other, and blacks over other incidence rates (2.01, 2.17), (2.23, 2.43), (1.05, 1.18). The corresponding one-sided hypotheses resulted in every case in $\mathrm{p}<0.0001$ as evidenced by the not containing CI's.

For the 1973-2010 period a total of 49,531 brain and CNS tumors were reported by the SEER registries with the resulting incidence rate of 6.14 (95\% CI 6.08 - 6.19) cases per 100,000 person-years. The detailed distribution of tumors by histology, race, sex, age group is presented in Table 1 . The most common histology has been

Table 1. Characteristics of the study population by histology, race, gender and age at diagnosis, SEER 1973-2010.

\begin{tabular}{ccccccccc}
\hline Site Group & \multicolumn{3}{c}{ Age at Diagnosis } & & Gender & \multicolumn{2}{c}{ Race } \\
& $\mathbf{0}-\mathbf{1 9}$ & $\mathbf{2 0 - 6 4}$ & $>\mathbf{6 5}$ & Males & White & Black & Total \\
Specified low grade astrocytic tumor & 1820 & 1743 & 347 & 56.31 & 86.67 & 6.98 & 3910 \\
Glioblastoma and anaplastic astrocytoma & 605 & 14,858 & 12,496 & 57.11 & 91.41 & 4.67 & 27,959 \\
Astrocytoma NOS & 1315 & 5165 & 2385 & 55.13 & 89.29 & 6.62 & 8865 \\
Other Glioma & 1399 & 5544 & 1971 & 54.68 & 87.18 & 6.44 & 8914 \\
Ependynoma & 588 & 1204 & 184 & 55.06 & 84.36 & 8.55 & 1976 \\
Medulloblastoma & 999 & 398 & 6 & 62.29 & 82.89 & 8.62 & 1403 \\
Supratentorial PNET & 434 & 221 & 25 & 57.94 & 79.85 & 10.15 & 680 \\
Other specified intracranial and intraspinal neoplasms & 145 & 726 & 578 & 44.24 & 77.92 & 13.87 & 1449 \\
Unspecified malignant intracranial intraspinal neoplasm & 122 & 618 & 1447 & 45.68 & 87.42 & 7.82 & 2187 \\
Total & 7427 & 30,477 & 19,439 & 55.47 & 89.02 & 6.05 & 57,343 \\
\hline
\end{tabular}

Brain and CNS primary brain tumors were according to adolescents and young adults (AYA) site recode. The sum of the subgroups does not equal the total since certain tumor types are not represented on the table. 
glioblastoma and anaplastic astrocytoma with 23,656 cases diagnosed resulting in 2.93 (95\% CI 2.89 - 2.96) cases per 100,000 person-years, followed by astrocytoma NOS with 8,430 cases resulting in 1.04 cases (95\% CI 1.02 - 1.07) per 100,000 person-years. Less common histology types have been supratentorial PNET with 0.07 cases (95\% CI 0.06 - 0.07), medulloblastoma 0.16 (95\% CI 0.15 - 0.17), and other specified intracranial and intraspinal neoplasms 0.16 (95\% CI 0.15 - 0.17), with 574, 1267, 1274 cases, respectively. Glioblastoma showed similar variation (rates between 2.5 and 3.6) in data from six cancer registries for the years 1985-1999 of the central brain tumor registries of the United States (CBTRUS), while in the same dataset the rate of astrocytoma NOS was reported between 0.4 and 1.7 [52] [53].

\subsection{Incidence Rates by Race and Gender}

In Table 2 we compare rates in different races and display relative risks by sex for nine histological types of brain tumors. The most common histologically confirmed tumor types, glioblastoma and anaplastic astrocytoma, have been much more frequent in white populations than any other tumor type, while this relationship is roughly inverted for supratentorial PNET, finally for other specified intracranial and intraspinal neoplasms, medulloblastoma and unspecified malignant intracranial and intraspinal neoplasms the incidence rate appeared to be equal. Most of the histology types are more frequent in males as the rates ratios clearly show; however, for other specified intracranial and intraspinal neoplasms and unspecified malignant intracranial and intraspinal neoplasms incidence rates for females are higher, see [54] for similar results from the central brain tumor registry of the USA. In Table 3 we summarize comparisons of rates by race and sex for all the histology types.

Table 2. Relative risk of brain and CNS tumors in relation to gender and race.

\begin{tabular}{ccccccccc}
\hline Site Group & \multicolumn{3}{c}{ Gender } & \multicolumn{3}{c}{ Race } \\
\hline & Male & Female & Ratio & White & Black & Other \\
Specified low grade astrocytic tumor & 0.45 & 0.39 & 1.22 & 0.47 & 0.24 & 0.22 \\
Glioblastoma and anaplastic astrocytoma & 4.07 & 2.55 & 1.38 & 3.56 & 1.72 & 1.43 \\
Astrocytoma NOS & 1.15 & 0.85 & 1.28 & 1.09 & 0.65 & 0.41 \\
Other Glioma & 1.15 & 0.87 & 1.26 & 1.08 & 0.61 & 0.64 & 0.14 \\
Ependynoma & 0.24 & 0.19 & 1.35 & 0.23 & 0.16 & 0.12 \\
Medulloblastoma & 0.18 & 0.11 & 1.67 & 0.16 & 0.10 & 0.16 \\
Supratentorial PNET & 0.08 & 0.06 & 1.50 & 0.07 & 0.06 & 0.07 \\
Other specified intracranial and intraspinal neoplasms & 0.16 & 0.17 & 0.82 & 0.16 & 0.26 & 0.15 \\
Unspecified malignant intracranial intraspinal neoplasm & 0.29 & 0.25 & 0.88 & 0.27 & 0.26 & 0.16
\end{tabular}

Incidence rates and relative risk by gender, and incidence rates depicted by race for nine histologies.

Table 3. Comparisons of primary brain and CNS tumors incidence rates by race and sex, SEER data.

\begin{tabular}{|c|c|c|c|c|c|c|c|}
\hline \multirow[t]{2}{*}{ Site Group } & \multicolumn{3}{|c|}{ Male } & \multicolumn{2}{|c|}{ Female } & \multirow[b]{2}{*}{ Other } & \multirow[b]{2}{*}{ Total } \\
\hline & White & Black & Other & White & Black & & \\
\hline Specified low grade astrocytic tumor & $0.50^{*}$ & 0.28 & 0.22 & $0.44^{* \neq}$ & 0.21 & 0.22 & 0.42 \\
\hline Glioblastoma and anaplastic astrocytoma & $4.47^{* \neq}$ & 2.15 & 1.77 & $2.81^{* \neq}$ & 1.39 & 1.15 & 3.23 \\
\hline Astrocytoma NOS & $1.27^{*} \neq$ & $0.74^{\times}$ & 0.46 & $0.93^{* \neq}$ & $0.57^{x}$ & 0.37 & 0.99 \\
\hline Other Glioma & $1.24^{* \neq}$ & 0.73 & 0.75 & $0.95^{* \neq}$ & 0.52 & 0.55 & 1.00 \\
\hline Ependynoma & $0.26^{*} \neq$ & 0.16 & 0.15 & $0.20^{\ddagger}$ & 0.16 & 0.13 & 0.22 \\
\hline Medulloblastoma & $0.20^{*}$ & 0.11 & 0.15 & 0.12 & 0.9 & 0.08 & 0.15 \\
\hline Supratentorial PNET & 0.09 & 0.06 & 0.08 & 0.06 & 0.06 & 0.06 & 0.07 \\
\hline Other specified intracranial and intraspinal neoplasms & 0.15 & $0.25^{\times}$ & 0.12 & 0.16 & 0.26 & 0.18 & 0.17 \\
\hline Unspecified malignant intracranial intraspinal neoplasm & $0.28^{*} \neq$ & 0.25 & 0.18 & $0.24^{* \neq}$ & 0.25 & 0.14 & 0.26 \\
\hline
\end{tabular}

Reported crude rates are per 100,000 person year. $\mathrm{p}<0.05$ for statistically significant difference between sexes and races. The table is structured with the following interpretation for its contents. Incidence rates in bold indicate significantly different rates between male and female of the same race for the type of brain tumor. Rates are noted with ${ }^{*}$ and ${ }^{\neq}$in whites for differences with blacks and others, while ${ }^{\times}$in blacks notes differences with others. 
The reported differences in incidence rates between races and sexes especially for some histological types illustrate significant variation across the contributing registries. For all the reported histologies the incidence rate for white males are significantly higher than the rates for white females. For the following histologies: glioblastomas and anaplastic astrocytomas, specified low grade astrocytic tumors, astrocytomas NOS and other gliomas, the significantly different incidence rate pairs among the three races are the same in both male and female populations. The ratios of the rates were tested assuming Poisson counts for the two populations at risk. The alternative hypothesis is the true ratio is not equal to one, which we accepted when the p-value is smaller than 0.05 [51]. A uniformly most powerful unbiased (UMPU) test for equality of two Poisson rates derived in [55], [56] are recent developments of the test for unequal sampling frames.

Higher incidence rates in males compared with females in the white race are statistically significant for all types of tumors $(\mathrm{p}<0.05)$. In contrast, gender specific rates for the black race do not significantly differ for specified low grade astrocytic tumor, ependynoma, supratentorial PNET, other specified and unspecified intracranial and intraspinal neoplasms. Gender differences were only apparent for the most common histologies, glioblastoma and other glioma, for the other race. Male predominance in glioblastoma and anaplastic astrocytoma, with a male to female ratio between 1.5 and 2.0 has been reported in [9] [13].

Incidence rates that differ $(\mathrm{p}<0.05)$ by race for the same sex are also presented in Table 3 . For the three most frequently reported histologies: glioblastoma and anaplastic astrocytoma, astrocytoma NOS and other glioma there are commonalities in the pairwise racial differences between males and females. Specifically, rates for both sexes in whites are higher than those of the remaining two races, whereas rates for the black race are different than that for other race only for astrocytoma NOS. Racial difference between blacks and others were not identified in any other case most likely because of the small number of cases that were diagnostically confirmed. Incidence of glioblastoma or anaplastic astrocytoma among Caucasians has been previously reported twice than that among African Americans [57] [58].

The white predominance in incidence rates is confirmed with significantly higher rates for unspecified malignant intracranial intraspinal neoplasms (rates for the black race are also significantly higher than rates for the other race), and specified low grade astrocytic tumors. For medulloblastoma, the most common pediatric tumor, significantly different racial pairs are between white and black males. With regard to observed patterns in racial differences of ependymomas, rates are higher among whites in both sexes than the other race. In the current study, the remaining racial differences are not common in both sexes.

Unspecified malignant intracranial and intraspinal neoplasms presented different rates for every racial pair we compared, white-black, white-other, black-other in both sexes. Other specified intracranial and intraspinal neoplasms while accounting only for $2.6 \%$ of the cases have observed rates different compared with other reported histologies. These differences may be due to variation in reporting, or even, frequently underreported tumors in patients. Race specific rates are significantly higher for black than white females. In addition, rates for black males are higher too, however the difference is not significant.

Although variation in the diagnoses may have larger influence than in clinical or institutional settings, the accurate identification of differing patterns in the rates may have implications about the disease in the general population. The large number of cases which are reported as astrocytoma NOS (17\%) or unspecified (3.7\%) in these data suggest that certain histologies are underreported. On the other hand, there are histologies like supratentorial PNET (1.1\%) for which an obstacle to overcome is obtaining a sufficient number of cases (the data set included 574 cases for the 34 years) to perform an analysis with adequate power.

\subsection{Variations of Incidence by Age at Diagnosis}

In the following paragraphs we will compare incidence rates between three age groups and examine the resulting rates for both sexes and races for the histologies of interest. The age-group specific incidence rates are in most cases similar to the overall rates, but in a few cases we identified sharp changes in incidence. In [59] a review of glioma, ependymoma, and medulloblastoma, highlights the differences between adults and children, including the higher incidence of spinal cord ependymoma and supratentorial high-grade glioma in the adults and a higher incidence of medulloblastoma in the children.

Regardless of sex or race the incidence rates for young patients diagnosed with specified low grade astrocytic tumors peak around the age of five. Nevertheless, the rate at this age is higher in females than males for the three 
races we have considered. Age-specific weighted average rates for both sexes were higher in six out of twenty one instances for the young age group for females than males, in contrast with the incidence rates relation reported in Table 3. For the two remaining age groups the incidence rate is fairly constant at about 0.3 per 100,000 person years with no significant differentiation in gender and race.

Glioblastomas and anaplastic astrocytomas are the most common types of brain tumors diagnosed in the USA. While the incidence rates for the young age group do not differ by sex or race, there is an impressive increase of the rates for the adult age group especially for white males (the incidence rate increases more than four times between the ages of 45 and 65, while the increase is two-fold for black males). For the elderly, the incidence continues to rise for both sexes until the age of 75 with a ratio of 2:1 for males over females, also for white over black and other race. Tumors of this type are frequently occurring in the other two racial groups for young ages, especially between the ages of five and ten.

Regardless of the gender of the patient, the next most common tumor type is astrocytoma NOS with median age at diagnosis 9.5, 42 and 75 for the three age groups. The comparison of incidence rates for different age groups remains as reported in Table 3 . The incidence increases sharply with age and peaks at the age of 65 with an incidence ratio five times that of the age of 20, this effect is pronounced in all the races. Incidence rate for other glioma young patients is higher between the ages of 5 to 10 . Interestingly enough the rate for this age is higher in blacks than any other race in contrast to the analysis presented in Table 3. The average age-specific incidence rates for males and females for the three races depicted those differences; the average rate for blacks is the highest in about half of the 21 computed rates. For the ages between 20 and 65 there is an increase of the incidence rate with a magnitude of 4 and 2 for males and females respectively.

Ependymomas are most common before the age of 5 during the lifetime, even though there seems to be a secondary peak for the incidence rate between the ages of 50 and 55, regardless of the sex and the race of the individual. When plotting incidence rates for white and black females, see Figure 1, we observed higher rates for black than white females of younger age where most of the tumors actually occur, this behavior was not observed in the male population. Medulloblastomas are diagnosed mainly in young patients, especially males around the age of 5 , are less common in adults, becoming exceptionally rare for the elderly. The average age at diagnosis with medulloblastoma is higher for young males than young females $(\mathrm{p}<0.05)$. We also noticed that ependymomas in males are likely to occur earlier than in females, while the converse is true for medulloblastoma. See [19] for a detailed analysis of pediatric brain tumors.

Young patients are the majority diagnosed with supratentorial PNET, though there is an insufficient number

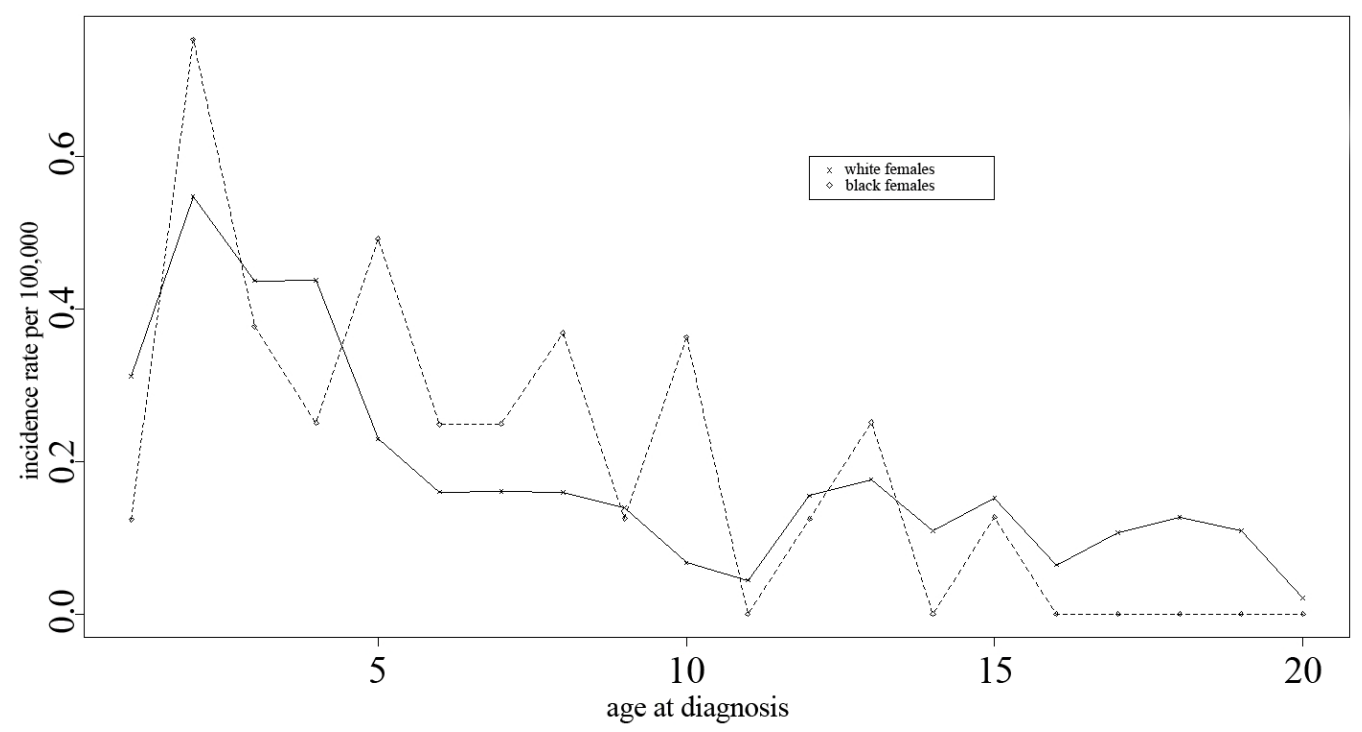

Figure 1. Incidence rates of primary ependymomas for the 0 - 19 age group. While estimated incidence rates are higher for white than black females, the converse is true for the young ages. The peak before the age of five is prominent for all the races and sexes. Rates are per 100,000 person years using the 2000 US standard population on single years of age, SEER data. 
of cases to identify significant differences between racial and gender subgroups for this histology. Other specified intracranial and intraspinal neoplasms most commonly occur before the age of 5 in females especially, with a secondary peak at the age of 65 . Black patients were more often diagnosed with other specified intracranial and intraspinal neoplasms. In Figure 2 we plot averaged rates of two sexes for the three races. In more detail, incidence rates for young white females are higher than white males of the same age, while rates for middle aged male whites are higher than middle aged white females. In the case of black middle-aged population the female rate is higher than the rate for males.

Incidence of unspecified malignant intracranial intraspinal neoplasms increases with age especially for black patients, rates rise abruptly after the age of 65 . For both the malignant intracranial and intraspinal neoplasms and the benign/border intracranial and intraspinal neoplasms we noticed a divergence between the rates for males and females in the young age groups; specifically, there is a higher number of young males than young females diagnosed with the aforementioned histologies.

\section{Discussion}

The study demonstrated an approach to understanding the patterns apparent in centralized data collections for statistical compilation on incidence of tumors. This report documented incidence of primary brain and CNS tumors, confirmed analyses in different subpopulations, even further noted separated trends in incidence for histology groups and age at diagnosis. The interpretation of incidence patterns is dependent on technological improvements, which alter the accuracy of the information over time, and the artificial spread of the tumor in the population because of changes in the classifications and coding. We have based our search on overall and histology specific incidence rates of primary brain tumors from the SEER data for the USA.

For the study period, overall incidence rates were higher for males than females, the observed histology-specific incidence rates are generally reported higher for whites than the other races. The observed patterns in the overall race and gender specific incidence were not always consistent with our analysis of incidence rates by age. Notably, we found that black females were predominant in other specified intracranial and intraspinal neoplasms, this change in the pattern of incidence is mostly evident after the age of forty-five. Overall, racial and gender

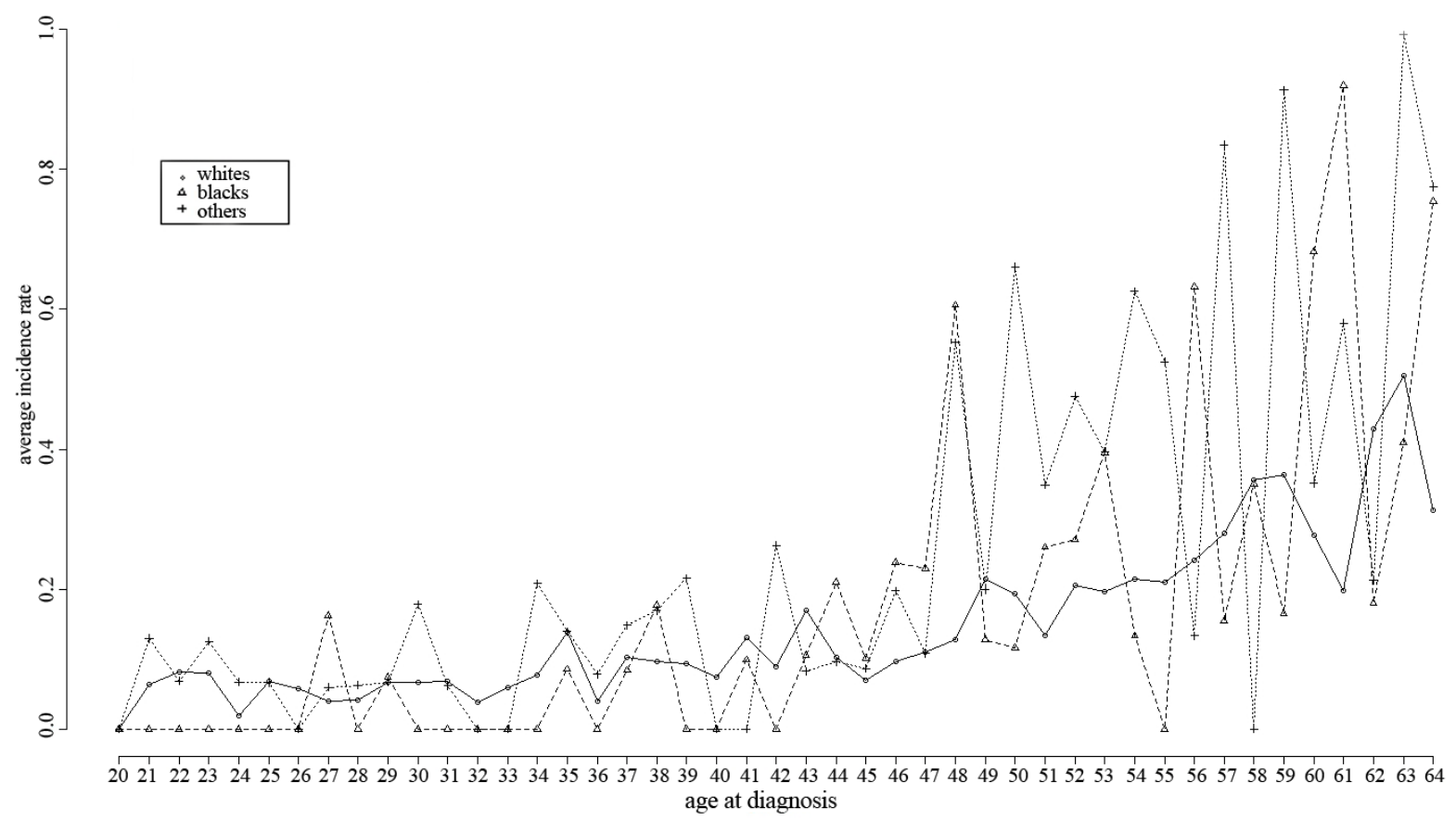

Figure 2. Averaged incidence rates of primary other specified intracranial/intraspinal neoplasms for the 20 - 64 age group. Estimated average rates for three races depict rates for young white females higher than white males of the same age, while rates for middle-aged male whites are higher than middle aged white females. In the case of black middle-aged population rate for females is higher than the rate for males. 
factors, play a major role but do not appear to be consistently linked with observed differences in brain cancer incidence. Statistically significant difference in rates for all races and sexes were identified in astrocytomas NOS and for unspecified malignant intracranial intraspinal neoplasms in females.

Estimated age specific rates of primary specified low grade astrocytic tumors peaked at the age of five, especially prominent for the white and other races, on the other hand, the incidence picture that emerged by gender was one of female predominance at that age. We documented age specific rates of primary other gliomas where the peak at the age of five is especially prominent for the black race, in contrast to overall incidence rates. Age specific rates of primary ependymomas raise some concerns; incidence rates are significantly higher for white females than black females, the converse is true for the young ages. Analyses of age specific incidence rates by histology confirmed that the timing and impact of factors influencing incidence rates differ significantly among races and sexes. Differing patterns in statistically significant histology specific incidence rates were identified, although rates for whites compared to other races were higher for several histologies, the current report demonstrated at least one change where the proportion for blacks was bigger.

We observed a substantial amount of deviation in the incidence rates of brain tumors for young patients in contrast to the consistently observed sex and racial differences indicated by the overall rates. However, a major obstacle for formulating and evaluating explanations is the rarity of those tumors diagnosed in young patients. Further examination of the racial and gender differences for incidence in this age group using the broadest data available would enhance our understanding of the established demographic variables.

We explored in detail histology-specific incidence patterns for various subgroups of the population. To assess data on incidence that are currently available in the United States, compare the number of cases by tumor subtype and analyze such patterns in similar patient populations it is necessary to further separate artificial changes from true ones. Comprehensive comparisons of the information from different resources are of great importance for research associated with brain and CNS tumors to identify risk factors and their continuing influence.

\section{References}

[1] Kohler, B.A., Ward, E., McCarthy, B.J., Schymura, M.J., Ries, L.A.G., et al. (2011) Annual Report to the Nation on the Status of Cancer, 1975-2007, Featuring Tumors of the Brain and Other Nervous System. Journal of the National Cancer Institute, 103, 1-23. http://dx.doi.org/10.1093/jnci/djr077

[2] CBTRUS (2011) Statistical Report: Primary Brain and Central Nervous System Tumors Diagnosed in the US in 2004-2007. Central Brain Tumor Registry of the United States, Hinsdale.

[3] Davis, F.G., McCathry, B.J. and Berger, M.S. (1999) Centralized Databases Available for Describing Primary Brain Tumor Incidence, Survival, and Treatment: Central Brain Tumor Registry of the United States; Surveillance, Epidemiology, and End Results; and National Cancer Data Base. Neuro-Oncology, 1, 205-211.

[4] Darefsky, A. and Dubrow, R. (2009) International Variation in the Incidence of Adult Primary Malignant Neoplasms of the Brain and Central Nervous System. Cancer Causes Control, 20, 1593-1604. http://dx.doi.org/10.1007/s10552-009-9404-1

[5] Kaneko, S., Namura, K., Yoshimura, T. and Yamaguchi, N. (2000) Trend of Brain Tumor Incidence by Histological Subtypes in Japan: Estimation from the Brain Tumor Registry of Japan, 1973-1993. Journal of Nanoelectronics and Optoelectronics, 60, 61-69.

[6] Deltour, I., Johansen, C., Auvinen, A., Feychting, M., Klaeboe, L., et al. (2009) Time Trends in Brain Tumor Incidence Rates in Denmark, Finland, Norway and Sweden, 1974-2003. Journal of the National Cancer Institute, 101, 1721-1724. http://dx.doi.org/10.1093/jnci/djp415

[7] Ohgaki, H. and Kleihues, P. (2005) Genetic Pathways to Primary and Secondary Glioblastoma. The American Journal of Pathology, 170, 1445-1453. http://dx.doi.org/10.2353/ajpath.2007.070011

[8] Watanabe, T., Nobusawa, S., Kleihues, P. and Ohgaki, H. (2009) $I D H_{1}$ Mutations Are Early Events in the Development of Astrocytomas and Oligodendrogliomas. The American Journal of Pathology, 174, 1149-1153. http://dx.doi.org/10.2353/ajpath.2009.080958

[9] Ohgaki, H. and Kleihues, P. (2005) Population-Based Studies on Incidence, Survival Rates and Genetic Alterations in Astrocytic and Oligodendroglial Gliomas. Journal of Neuropathology Experimental Neurology, 64, 479-489.

[10] Lehrer, S., Green, S., Ramanathan, L., Rosenzweig, K. and Labombardi, V. (2012) No Consistent Relationship of Glioblastoma Incidence and Cytomegalovirus Seropositivity in Whites, Blacks and Hispanics. International Journal of Cancer Research and Treatment, 32, 1113-1115.

[11] Sun, T., Warrington, N.M. and Rubin, J.B. (2012) Why Does Jack, and Not Jill, Break His Crown? Sex Disparity in 
Brain Tumors. Biology of Sex Differences, 3, 3.

[12] Schwartzbaum, J.A., Fisher, J.L., Aldape, K.D. and Wrensch, M. (2006) Epidemiology and Molecular Pathology of Glioma. Nature Clinical Practice Neurology, 2, 494-503. http://dx.doi.org/10.1038/ncpneuro0289

[13] Hochberg, F.H., Baehring, J.M. and Hochberg, E.P. (2007) Primary CNS Lymphoma. Nature Reviews Neurology, 3, 24-35. http://dx.doi.org/10.1038/ncpneuro0395

[14] Khurana, V.G., Charles, T., Kundi, M., Hardell, L. and Carlberg, M. (2009) Cell Phones and Brain Tumors: A Review Including the Long-Term Epidemiologic Data. Surgical Neurology, 72, 205-214. http://dx.doi.org/10.1016/j.surneu.2009.01.019

[15] Little, M.P., Rajaraman, P., Curtis, R.E., Devesa, S.S., Inskip, P.D., et al. (2012) Mobile Phone Use and Glioma Risk: Comparison of Epidemiological Study Results with Incidence Trends in the United States. British Medical Journal, 344, Article ID: e1147. http://dx.doi.org/10.1136/bmj.e1147

[16] Kan, P., Simonsen, S.E., Lyon, J.L. and Kestle, J.R.W. (2008) Cellular Phone Use and Brain Tumor: A Meta-Analysis. Journal of Neuro-Oncology, 86, 71-78. http://dx.doi.org/10.1007/s11060-007-9432-1

[17] Ahlbom, A., Feychting, M., Green, A., Kheifetl, L., Savitz, D.A., et al. (2009) Epidemiologic Evidence on Mobile Phones and Tumor Risk: A Review. Epidemiology, 20, 639-652. http://dx.doi.org/10.1097/EDE.0b013e3181b0927d

[18] Inskip, P.D., Hoover, R.N. and Devesa, S.S. (2010) Brain Cancer Incidence Trends in Relation to Cellular Telephone Use in the United States. Neuro-Oncology, 12, 1147-1151. http://dx.doi.org/10.1093/neuonc/noq077

[19] Smith, M.A., Seibel, N.L., Altekruse, S.F., Ries, L.A.G., Melbert, D.L., et al. (2010) Outcomes for Children and Adolescents with Cancer: Challenges for the Twenty-First Century. Journal of Clinical Oncology, 28, 2625-2634. http://dx.doi.org/10.1200/JCO.2009.27.0421

[20] Bishop, A.J., McDonald, M.W., Chang, A.L. and Esiashvili, N. (2012) Infnant Brain Tumors: Incidence, Survival and the Role of Radiation Based on Surveillance, Epidemiology and End Results (SEER) Data. International Journal of Radiation Oncology Biology Physics, 82, 341-347. http://dx.doi.org/10.1016/j.ijrobp.2010.08.020

[21] Kaatsch, P. (2010) Epidemiology of Childhood Cancer. Cancer Treatment Reviews, 36, 277-285. http://dx.doi.org/10.1016/j.ctrv.2010.02.003

[22] Merchant, T.E., Pollack, I.F. and Loeffler, J.S. (2010) Brain Tumors across the Age Spectrum: Biology, Therapy and Late Effects. Seminars in Radiation Oncology, 20, 58-66. http://dx.doi.org/10.1016/j.semradonc.2009.09.005

[23] Pollack, I.F. and Jakacki, R.I. (2011) Childhood Brain Tumors: Epidemiology, Current Management and Future Directions. Nature Reviews Neurology, 7, 495-506. http://dx.doi.org/10.1038/nrneurol.2011.110

[24] Holmes Jr., L., Hossain, J. and Franklin, O. (2012) Pediatric Thyroid Carcinoma Incidence and Temporal Trends in the USA (1973-2007): Race or Shifting Diagnostic Paradigm? International Scholarly Research Network Oncology, 2012, $1-10$.

[25] Linabery, A.M. and Ross, J.A. (2008) Trends in Childhood Cancer Incidence in the US (1992-2004). Cancer, 112, 416-432. http://dx.doi.org/10.1002/cncr.23169

[26] Bauchet, L., Rigau, V., Mathieu-Daude, H., Fabbro-Peray, P., Palenzuela, G., et al. (2009) Clinical Epidemiology for Childhood Primary Central Nervous System Tumors. Journal of Neuro-Oncology, 92, 87-98. http://dx.doi.org/10.1007/s11060-008-9740-0

[27] Hoffman, S., Propp, J.M. and McCarthy, B.J. (2006) Temporal Trends in Incidence of Primary Brain Tumors in the United States, 1985-1999. Neuro-Onchology, 8, 27-37. http://dx.doi.org/10.1215/S1522851705000323

[28] Hess, K.R., Broglio, K.R. and Bondy, M.L. (2000) Adult Glioma Incidence Trends in the United States, 1977-2000. Cancer, 101, 2293-2299. http://dx.doi.org/10.1002/cncr.20621

[29] Hoffman, S., Propp, J.M. and McCarthy, B.J. (2006) Temporal Trends in Incidence in Primary Brain Tumors in the United States, 1985-1999. Neuro-Oncology, 8, 27-37. http://dx.doi.org/10.1215/S1522851705000323

[30] McCarthy, B.J., Propp, J.M., Davis, F.G. and Berger, P.C. (2008) Time Trends in Oligodendroglial and Astrocytic Tumor Incidence. Neuroepidemiology, 30, 34-44. http://dx.doi.org/10.1159/000115440

[31] Hsu, S., Quattrone, M., Ostrom, Q., Ryken, T.C., Sloan, A.E., et al. (2011) Incidence Patterns for Primary Malignant Spinal Cord Gliomas: Surveilance, Epidemiology and End Results Study. Journal of Neurosurgery:Spine, 14, 742-747. http://dx.doi.org/10.3171/2011.1.SPINE10351

[32] Deborah, S., Lynch, C.F., Sibenaller, Z.A. and Ryken, T.C. (2006) Trends in Brain Cancer Incidence and Survival in the United States: Surveillance, Epidemiology and Ends Results Program, 1973 to 2001. Neurosurgical Focus, 20, E1. http://dx.doi.org/10.3171/foc.2006.20.4.E1

[33] Ostrom, Q.T. and Barnholtz-Sloan, J.S. (2011) Current State of Our Knowledge on Brain Tumor Epidemiology. Current Neurology and Neuroscience Reports, 11, 329-335. http://dx.doi.org/10.1007/s11910-011-0189-8

[34] Bondy, M.L., Scheurer, M.E., Malmer, B., Barnholtz-Sloan, J.S., Davis, F.G., et al. (2008) Brain Tumor Epidemiology: 
Consensus from the Brain Tumor Epidemiology Consortium. Cancer, 113, 1953-1968. http://dx.doi.org/10.1002/cncr.23741

[35] Claus, E.B., Abdel-Wahab, M., Burger, C.P., Engelhard, H.H., Ellison, D.W., et al. (2010) Defining Future Directions in Spinal Cord Tumor Research Proceedings from the National Institutes of Health Workshop. Journal of Neurosurgery: Spine, 12, 117-121. http://dx.doi.org/10.3171/2009.7.SPINE09137

[36] Wrensch, M., Minn, Y., Chew, T., Bondy, M., Berger, M.S., et al. (2002) Epidemiology of Primary Brain Tumors: Current Concepts and Review of the Literature. Neuro-Oncology, 4, 278-299.

[37] Ottaviani, G. and Jaffe, N. (2010) The Epidemiology of Osteosarcoma. Cancer Treatment and Research, 152, 3-13. http://dx.doi.org/10.1007/978-1-4419-0284-9_1

[38] Keene, D.L. and Johnston, D. (2012) Central Nervous System Germ Cell Tumors: An Epidemiology Review. Tumors of the Central Nervous System, 5, 95-98.

[39] Baldi, I. and Loiseau, H. (2012) Epidemiology of Primary Brain Tumors. Tumors of the Central Nervous System, 4, 313.

[40] Fisher, J.L., Scwwatzbaum, J.A., Wrensch, M. and Wiemeles, J.L. (2007) Epidemiology of Brain Tumors. Neurologic Clinics, 25, 867-890. http://dx.doi.org/10.1016/j.ncl.2007.07.002

[41] Brown, M., Schrot, R., Bauer, K. and Letendre, D. (2009) Incidence of First Primary Central Nervous System Tumors in California, 2001-2005. Journal of Neuro-Oncology, 94, 249-261. http://dx.doi.org/10.1007/s11060-009-9864-X

[42] McGuire, C.S., Sainani, K.L. and Fisher, P.G. (2009) Incidence Patterns for Ependymoma: A Surveillance, Epidemiology and End Results Study. Journal of Neurosurgery, 110, 725-729. http://dx.doi.org/10.3171/2008.9.JNS08117

[43] Schellinger, K.A., Propp, J.M., Villano, J.L. and McCarthy, B.J. (2008) Descriptive Epidemiology of Primary Spinal Cord Tumors. Journal of Neuro-Oncology, 87, 173-179. http://dx.doi.org/10.1007/s11060-007-9507-z

[44] Villano, J.L., Virk, I.Y., Ramirez, V., Propp, J.M., Engelhard, H.H., et al. (2010) Descriptive Epidemiology of Central Nervous System Germ Cell Tumors: Nonpineal Analysis. Neuro-Oncology, 12, 257-264. http://dx.doi.org/10.1093/neuonc/nop029

[45] Villano, J.L., Bressler, L., Propp, J.M., Valyi-Nagy, T., Martin, I.K., et al. (2010) Descriptive Epidemiology of Selected Olfactory Tumors. Journal of Neuro-Oncology, 100, 73-80. http://dx.doi.org/10.1007/s11060-010-0140-x

[46] Caldarella, A., Crocetti, E. and Paci, E. (2011) Is the Incidence of Brain Tumors Really Increasing? A Population-Based Analysis from a Cancer Registry. Journal of Neuro-Oncology, 104, 589-594. http://dx.doi.org/10.1007/s11060-011-0533-5

[47] Gurney, J.G. and Kadan-Lottick, N. (2001) Brain and Other Central Nervous System Tumors: Rates, Trends and Epidemiology. Current Opinion in Oncology, 13, 160-166. http://dx.doi.org/10.1097/00001622-200105000-00005

[48] Fritz, A., Percy, C., Jack, A., Shanmugarathnam, K., Sobin, L., et al. (2000) International Classification of Diseases for Oncology. 3rd Edition, World Health Organization, Geneva.

[49] Barr, R.D., Holowaty, E.J. and Birch, J.M. (2006) Classification Scheme for Tumors Diagnosed in Adolescents and Young Adults. Cancer, 106, 1425-1430. http://dx.doi.org/10.1002/cncr.21773

[50] Surveillance, Epidemiology, and End Results (SEER) Program (www.seer.cancer.gov) SEER*Stat Database: Incidence -SEER 9 Regs Research Data, Nov 2012 Sub (1973-2010) "Katrina/Rita Population Adjustment”-Linked to County Attributes-Total US, 1969-2011 Counties, National Cancer Institute, DCCPS, Surveillance Research Program, Surveillance Systems Branch, Released April 2013, Based on the November 2012 Submission.

[51] Lehmann, E.L. and Romano, J.P. (2005) Testing Statistical Hypotheses. Springer, New York.

[52] Surawicz, T.S., McCarthy, B.J., Kupelian, V., Jukich, P.J., Bruner, J.M., et al. (1999) Descriptive Epidemilology of Primary Brain and CNS Tumors: Results from the Central Brain Tumor Registry of the United States, 1990-1994. Neuro-Oncology, 1, 14-25.

[53] Jukich, P.J., McCarthy, B.J., Surawicz, T.S., Freels, S. and Davis, F.G. (2001) Trends in Incidence of Primary Brain Tumors in the United States, 1985-1994. Neuro-Oncology, 3, 141-151.

[54] Surawicz, T.S., Davis, F., Freels, S., Laws Jr., E.R. and Menck, H.R. (1998) Brain Tumor Survival: Results from the National Cancer Data Base. Journal of Neuro-Oncology, 40, 151-160. http://dx.doi.org/10.1023/A:1006091608586

[55] Shiue, W.K. and Bain, L.J. (1982) Experiment Size and Power Comparisons for Two-Sample Poisson Test. Applied Statistics, 31, 131-134.

[56] Krishnamoorthy, K. and Thomson, J. (2004) A More Powerful Test for Comparing Two Poisson Means. Journal of Statistical Planning and Inference, 119, 23-35. http://dx.doi.org/10.1016/S0378-3758(02)00408-1

[57] Jemal, A., Siegel, R., Ward, E., Murray, T., Xu, J., et al. (2006) Cancer Statistics. A Cancer Journal for Clinicians, 56, 
106-130. http://dx.doi.org/10.3322/canjclin.56.2.106

[58] Legler, J.M., Gloeckler Reis, L.A., Smith, M.A., Warren, J.L., Heineman, E.F., et al. (1999) Brain and Other Central Nervous System Cancers: Recent Trends in Incidence and Mortality. Journal of the National Cancer Institute, 91, 1382-1389. http://dx.doi.org/10.1093/jnci/91.16.1382

[59] Ohgaki, H. and Kleihues, P. (2005) Epidemiology and Etiology of Gliomas. Acta Neuropathologica, 109, 93-108. http://dx.doi.org/10.1007/s00401-005-0991-y 